\title{
Mucor oblongisporus as a psychrophilic secondary sugar fungus
}

\author{
VeikkoHintikka
}

Finnish Forest Research Institute, Unioninkatu 40 A, Helsinki 17, Finland

\begin{abstract}
A strain of Mucor oblongisporus Naumov was isolated from snow-covered litter in Ruotsinkylä experimental forest near Helsinki, Finland.

Its temperature relations, maximum around $20^{\circ} \mathrm{C}$, optimum approximately $10^{\circ} \mathrm{C}$, growth still visible at $0^{\circ} \mathrm{C}$, indicate it to be a psychrophilic species.

The species utilizes several oligosaccharides, a notable exception being sucrose, on which no sporangia are developed. When certain other fungi are present on sucrose media, sporangia are developed vigorously, which is considered to indicate that the species is able to utilize glucose and fructose hydrolyzed from sucrose by other fungi.

No growth is obtained on media in which the sole source of carbon is cellulose. When certain wood-decomposing white-rot fungi are present, sporangia are produced abundantly. The effect of the other fungus does not depend on vitamins, as addition of glucose or vitamin-free media immediately initiates vigorous growth on a cellulose medium.

The species is evidently able to disperse spores along an ice surface in thin films of water. When a sporangium touches a piece of ice at $0^{\circ} \mathrm{C}$, spores are violently discharged along the water film and cracks in the ice. The sporangium makes a hole approximately $20 \mu$ deep in the ice.

The concepts of psychrophilic and secondary sugar fungus are discussed.
\end{abstract}

\section{Introduction}

The concept »sugar fungus» was introduced by Thom and Morrow in the year 1937, and later elaborated and established by BuRGES (1939, WAID 1968). Sugar fungi are among the first colonizers of vegetable litter and being fast-growing or sporulating species rapidly consume easily soluble organic nutrients, especially sugars, but also amino acids, starch, etc. They are generally considered to require an environment which is free from other fungi, and later in the fungal succession these first colonizers are suppressed by other species.

Secondary sugar fungi are defined by GARRETT (1963, p. 100) as fungi which are incapable of decomposing cellulose, and which live as dependants of cellulose-decomposing fungi, taking a share of the break- down products resulting from the hydrolysis of the cellulose. In contrast to sugar fungi, secondary sugar fungi are assumed to live in a highly competitive environment, where succes depends on such factors as the excretion of antibiotics and the tolerance of antibiotics produced by other micro-organisms. Although the existence of a group of fungi with this kind of ecology has often been assumed (WaID 1968, p. 305), knowledge of it is rather incomplete (GARRETT 1963). Mangenot (1952) recognizes a Mortierella ramanniana stage in the decomposition of wood, and the fungi present at this time, $M$. ramanniana, $M$. pusilla var. isabellina as well as Chaetomium, Fusarium and Cylindrocarpon spp., are supposed to utilize at least partly the metabolic products of earlier cellulose-decomposing fungi. According to Hudson (1968), certain species of 


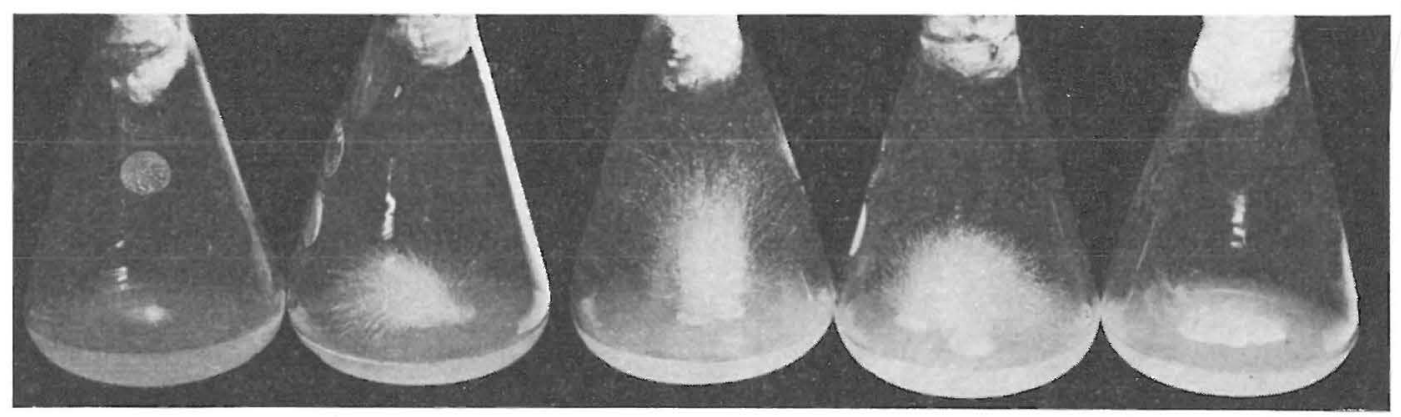

Fig. 1. Growth of Mucor oblongisporus at different temperatures. From left to right: $0^{\circ}, 5^{\circ}, 10^{\circ}, 15^{\circ}$, and $20^{\circ} \mathrm{C}$

Mucorales, appearing in the later stages of the fungal succession of plant remains, are evidently secondary sugar fungi.

In connection with investigations on psychrophilic fungi in forest soils (HintikKa 1964, Samipper \& HintikKa 1969) evidence has been brought that the peculiar fungal flora which is active under the snow cover may include unexplored forms. Among several species isolated from frozen forest soil, Mucor oblongisporus exhibited properties which suggest that it belongs to this flora.

\section{Methods}

In this investigation strain D5 of Mucor oblongisporus was used. The strain, obtained in 1966 from snow-covered birch litter in Ruotsinkylä experimental forest ( $24 \mathrm{~km}$ north of Helsinki), was isolated by incubating pieces of litter at $+5^{\circ} \mathrm{C}$ on Hagem agar. Abundant low-temperature basidiomycete mycelia, earlier described by HintikkA (1964), were met with in the same locality. The determination was confirmed at Centraalbureau voor Schimmelcultures,Baarn. As a standard medium Hagem agar was used, the composition of which is: glucose $5 \mathrm{~g}$, malt extract $5 \mathrm{~g}, \mathrm{NH}_{4} \mathrm{Cl}$ $0.5 \mathrm{~g}, \mathrm{MgSO}_{4} .7 \mathrm{H}_{2} \mathrm{O} 0.5 \mathrm{~g}, \mathrm{KH}_{2} \mathrm{PO}_{4} 0.5 \mathrm{~g}, \mathrm{FeCl}$ $1 \%$ solution $1 \mathrm{ml}$, agar $1.5 \mathrm{~g}$, disitilled water 1,000 ml. Stock cultures were kept at $+5^{\circ} \mathrm{C}$.

\section{Temperature relations}

Fig. 1 illustrates the growth of the aerial mycelium of Mucor oblongisporus at different temperatures, which were controlled with an accuracy of $\pm 1^{\circ} \mathrm{C}$. The optimum was around $10^{\circ} \mathrm{C}$, and at both $20^{\circ}$ and $0^{\circ}$ there was only slight submerged growth. The great sensitivity to heat is remarkably great, compared with that of other fungi, as in most other species the maximum is over $25^{\circ}$ C (Togashi 1949, Cochrane 1958).
Naumov (1954), who isolated this species both in February and in summer, does not mention the low maximum temperature, nor is it mentioned by GILman (1957) and Zycha (1963). At normal room temperatures of $22^{\circ}-25^{\circ} \mathrm{C}$, cultures are killed in about two weeks.

On several occasions low temperatures have been found to promote the development of larger spores. According to Williams (1959), the spore size of Mucor dispersus was distinctly larger at $10^{\circ} \mathrm{C}$ than at $25^{\circ} \mathrm{C}$. In the present investigation spore length was measured on cultures of $M$. oblongisporus in flasks kept at temperatures ranging from $5^{\circ}$ to $20^{\circ}, 300$ measurements being made for each temperature. The results were as follows:

$$
\begin{array}{lr}
+5^{\circ} \mathrm{G} & 12.1 \pm 0.104 \mu \mathrm{m} \\
+10^{\circ} \mathrm{C} & 10.0 \pm 0.093 \mu \mathrm{m} \\
+15^{\circ} \mathrm{G} & 10.0 \pm 0.082 \mu \mathrm{m} \\
+20^{\circ} \mathrm{G} & 9.9 \pm 0.080 \mu \mathrm{m}
\end{array}
$$

The difference between $5^{\circ}$ and $10^{\circ}$ is statistically significant $(\mathrm{P}<0.005)$. This phenomenon is evidently one of the factors causing variability noted in taxonomic investigations (Fig. 2).

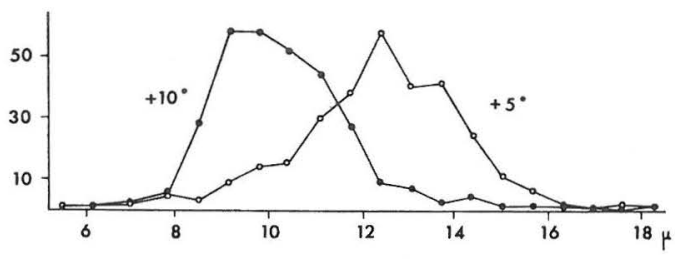

Fig. 2. Spore length of Mucor oblongisporus grown in $+5^{\circ}$ and $+10^{\circ} \mathrm{C}$. 


\section{Growth in different carbon sources}

Fig. 3 illustrates the growth of Mucor oblongisporus in media which consisted of mineral salts and agar of Hagem agar, autoclaved at $120^{\circ} \mathrm{C}$ for 20 minutes, and to which different carbohydrates were added after autoclavization, at temperatures of ca. $90^{\circ} \mathrm{C}$ and concentrations of 0.5 per cent. The carbohydrates used were obtained through Merck and Fluka AG:s and the quality was »purum» and »purissimum».

Glucose, fructose, maltose, galactose, sorbose, cellobiose, mannose and starch were utilized fairly well by the fungus. Lactose, raffinose, and sucrose did not support aerial mycelium, the hyphae growing totally submerged, and no sporangia were formed. It should be noted that if sucrose is autoclaved, abundant production of sporangia is obtained, evidently owing to the hydrolysis of the sucrose.

When sterilized vitamin-free casamino acid medium or vitamin-free yeast base (Difco) were added to the sucrose flask, vigorous development of aerial mycelium was obtained. This indicates that vitamin impurities are evidently not responsible for the different response. Probably the inability to utilize sucrose is due to the absence of the saccharase enzyme. Many species of Mucorales are known to be unable to utilize sucrose (Cochrane 1958), although they grow well on both of its components.

However, if there were certain other fungi on the same sucrose medium, Mucor produced abundant sporangia around the other fungus colony. In this regard Cladosporium sp. and Desmazierella acicola seemed to be fairly effective (Fig. 4). On the other hand, Trichoderma viride and Fomitopsis pinicola did not promote sporangiophore formation at all. Desmazierella occurs on newly fallen spruce needles, and Cladosporium is one of the first colonizers of leaf litter.

The enzyme saccharase occurs in soils (Stevenson 1964) and is probably connected with the activity of decomposing microorganisms. The present experiment suggests that Mucor is able to utilize the monosaccharides liberated by other fungi.

According to Hawker (1947), the fruiting of Melanospora destruens is greatly increased on sucrose medium, if species of Chaetomium, Pyronema, and Fusarium are grown together with Melanospora. These fungi are known to break down sucrose more rapidly than Melanospora.

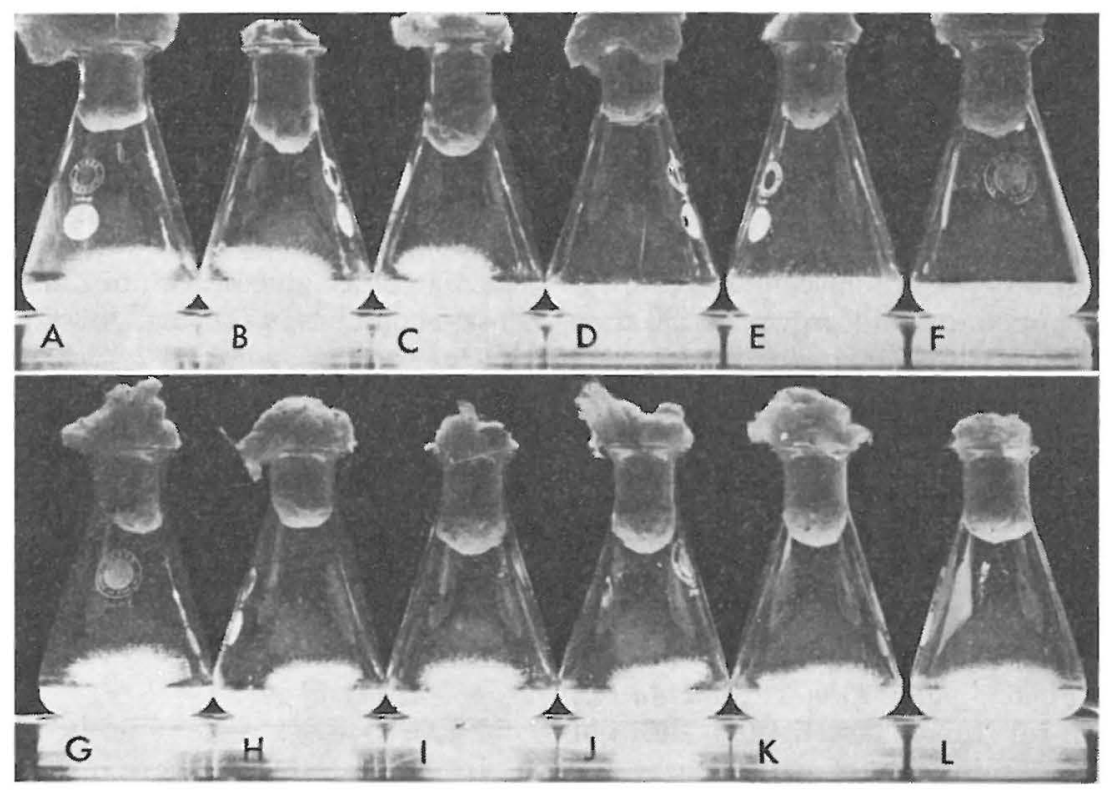

Fig. 3. Growth of Mucor oblongisporus on different carbon sources. a: cellobiose, b: xylose, c: mannose, d: lactose, e: raffinose, f: sucrose, g: maltose, h: glucose, i: fructose, $\mathrm{j}$ : galactose, $\mathrm{k}$ : sorbose, and 1: starch. Age of the cultures 12 days. 


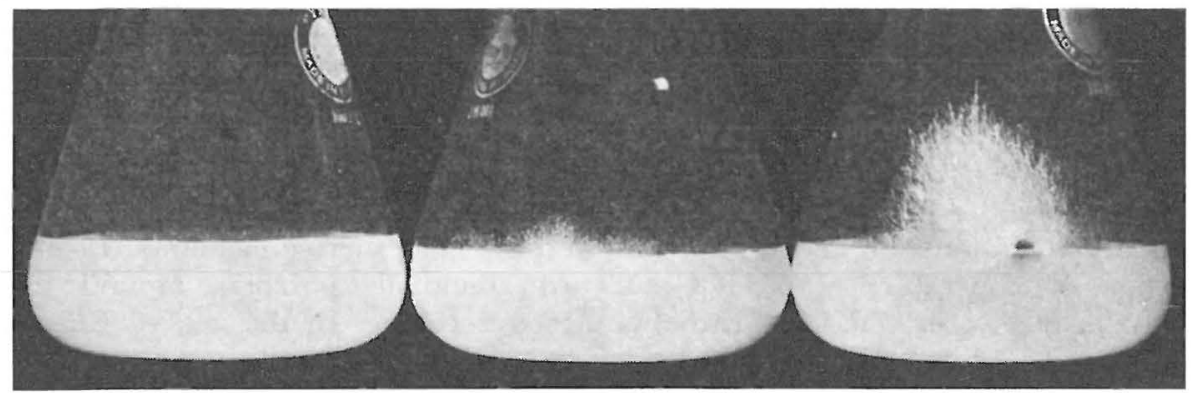

Fig. 4. Mucor oblongisporus grown on sucrose agar alone (lefit), together with Desmazierella acicola (centre) and Cladosporium sp. (right), which induced formation of sporangia of Mucor.

When Mucor was grown on sterilized litter to which after sterilization sterile distilled water was added, clearly visible aerial mycelium developed on leaf litter, especially on Alnus incana. On Pinus silvestris needles the growth was scarcely visible. According to Nykvist (1963), undecomposed leaf litter contains considerable amounts of glucose (4 $-9 \%$ dry weight), sucrose (in Betula litter $0.6 \%$ ), fructose and amino acids, which disappear rapidly in aerobic decomposition.

According to Naumov (1954), the species has been isolated from soil, grass, different decomposing organic remains, and dung. Puchko (1966) reports it from cabbage barrels.

When Mucor oblongisporus was grown on Hagem agar from which all carbon sources were omitted, and on which a sterilized filter paper was placed after the agar had solidified, no production of sporangia was observed, or only occasionally around the inoculum. If other basidiomycetes were inoculated on this medium and grown for 30 days at room temperature, and Mucor was then inoculated, in many cases vigorous development of sporangia was seen. Fig. 5 shows the amount of sporangia developed by Mucor oblongisporus when grown together with different species of cellulose-decomposing basidiomycetes for 18 days. The most suitable partners for Mucor seem to be certain whiterot fungi, e.g. Collybia butyracea, Coriolus hirsutus (Fig.6), and Fomes fomentarius. The brown-rot fungi investigated did not stimulate the production of sporangia to any important degree. The production of sporangia was especially vigorous when Mucor was grown together with an unidentified low- temperature basidiomycete, isolated from the same stand as Mucor.

As the stimulation of sporangia formation may depend on changes in $\mathrm{pH}$ or on vitamins, sterile solutions of glucose, vitaminfree yeast base (Difco), or vitamin-free casamino acids (Difco) were adided to the medium, whereupon Mucor produced abundant aerial mycelium. This indicates that Mucor primarily obtains soluble carbonhydrates from the other fungus.

According to VartiovaARA (1935), SiU (1951) and Cochrane (1958), several cellulose-decomposing fungi enrich the medium with sugars produced from cellulose. There are also indications that this may occur in forest soils, as considerable amounts of anthrone positive substances are found in humus decomposed by white-rot fungi (HrNTikka 1970). In the present experiment, the amount of substances which reduce Fehling's solution was determined in each flask and calculated as glucose. Uninoculated control flasks contained $7.0 \mathrm{mg}$, flasks with only Mucor oblongisporus $3.2 \mathrm{mg}$, flasks with only Coriolus hirsutus $40.4 \mathrm{mg}$ and flasks with both species $28.6 \mathrm{mg}$ reducing substances. The results suggest that carbon nutrition plays an important role in the development of Mucor when it is grown together with Coriolus hirsutus.

\section{Spore dispersal}

In general the mechanisms of spore dispersal in Mucorales are adapted to rather many different environmental conditions (Ingold \& Zoberi 1963). Mucor oblong- 


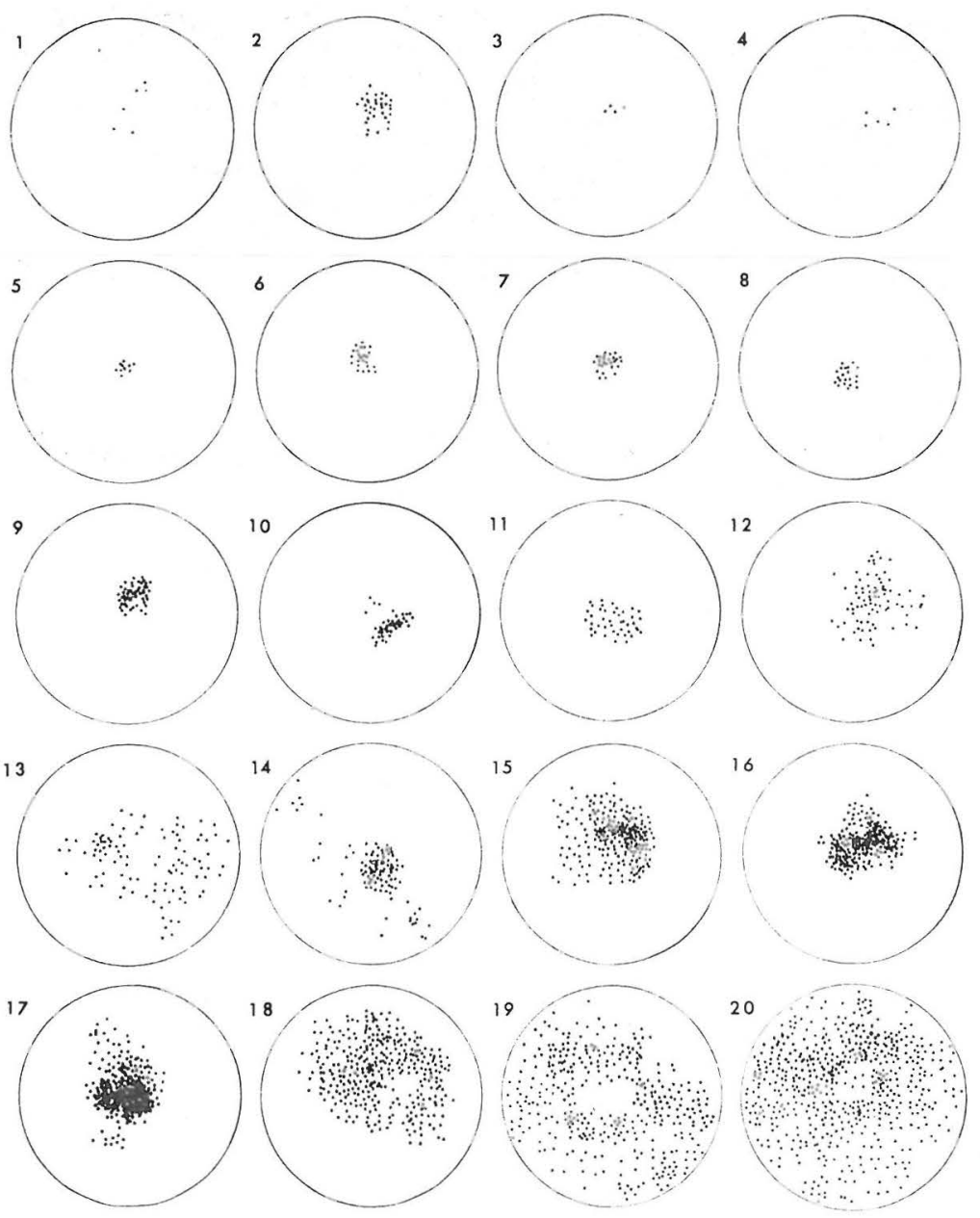

Fig. 5. Development of sporangia of Mucor oblongisporus (black points) on cellulose agar in petri dishes. 1 and 2: grown alone. Grown together with 3: Polyporus brumalis, 4: Marasmius prasiosmus, 5: Pleurotus mitis, 6: Phyllotopsis nidulans, 7: Fomes annosus, 8: Panus conchatus, 9: Poria vaporaria, 10: Marasmius bulliardii, 11: Laetiporus sulphureus, 12: Hohenbuehelia serotina, 13: Phellinus igniarius, 14: Collybia confluens, 15: Inonotus radiatus, 16: Aporpium semisupinum, 17: Polyporus hirsutus, 18: Fomes fomentarius, 19: Armillariella mellea, and 20: Collybia butyracea.

isporus is able to grow slowly around $0^{\circ} \mathrm{C}$. This temperature prevails for rather long periods at the snow-melting time in spring. In winter under thick snow cover the temperature may rise to $0^{\circ}$ for considerable periods, especially in certain years. In these conditions, the litter is mostly covered with ice.

When a sporangium of Mucor oblongisporus is placed on the surfare of ice at $0^{\circ} \mathrm{C}$, a violent discharge of spores is seen. Within a second or so, spores are distributed rapidly by melting water, travelling several centimetres from the sporangium along the thin surface film of water. In the same time, a hole develops in the ice at the place of the sporangium. An attempt was made to estimate the depth of this hole by the following method. Thin sheets of ice were prepared by dropping $10-50 \mathrm{mg}$ of distilled water on an object slide on an analytical balance, covering it rapidly with a cover glass of 


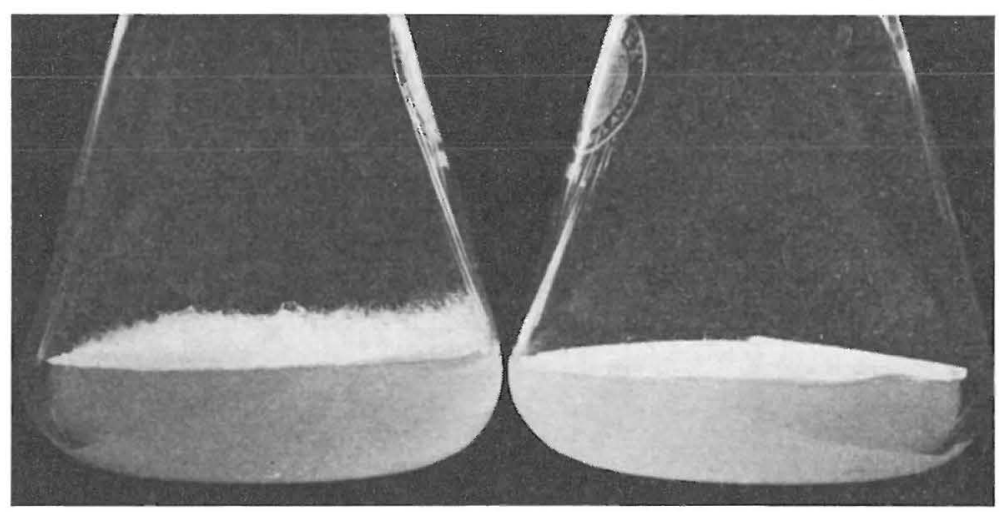

Fig 6. Mucor oblongisporus on cellulose agar alone (right) and together with Coriolus hirsutus (left). The main part of the aerial mycelium belongs to $M$. oblongisporus. Age of Coriolus 58 days, and that of Mucor 28 days.

known area, pressing it so that the water covered the whole of the cover glass, and putting it into $-20^{\circ} \mathrm{C}$. Free thin sheets of ice of known thickness were obtained by carefully pushing the ice sheet over the edge of the slide. It was found that the sporangia made holes in the sheets which were approximately $20 \mu$ thick, but not in those 100 $\mu$ in thickness. The reaction occurred only around $0^{\circ} \mathrm{C}$, and even at $-2^{\circ}$ the sporangium remained frozen on the surface of the ice.

\section{Discussion}

In fungal ecology the term psychrophilic is applied to those forms which have their optimum temperature for growth near or below $+10^{\circ} \mathrm{C}$, but usually also grow at temperatures of $20^{\circ}-25^{\circ} \mathrm{C}$ (Deverall 1968), as Phacidium infestans (PeHrson 1948). The contrasting term »thermophilic» is applied slightly differently to fungi whose minimum temperature is above room temperature, of which about twenty species are known (Cooney \& Emerson 1964). Evidently certain obligately psychrophilic fungi, which have a maximum growth temperature below $20^{\circ}$ $\mathrm{C}$, also occur but the psychrophilic fungal population has been much less thoroughly investigated than the industrially important thermophilic fungi.

The fact that Mucor oblongisporus is able to grow on cellulose only in the presence of certain other fungi, is a character suggestive of a secondary sugar fungus. Primary sugar fungi are not regarded as being able of growing with other fungi, being assumed to be intolerant of competition. At present it is not possible to decide definitely whether these two groups are really separate in regard to their physiology and ecology. Mucor oblongisporus is probably not an extreme type of secondary sugar fungus, as it is evidently able to a certain extent to grow as a primary sugar fungus on freshly fallen litter. Its inability to utilize some simple carbohydrates suggests that secondary sugar fungi may have a more restricted capacity for using different carbon sources than primary sugar fungi. However, it was not possible to determine in this study whether this is an ecological handicap or whether the lack of certain enzymes enables the species to withstand the antibiotics of other fungi. The absence of enzymes which split non-toxic glycosides into toxic compounds has been regarded as an advantage for certain parasitic fungi.

The decomposition of cellulose in nature is regarded as a symbiontic process, in which several organisms participate (Siu 1951, GasCoIGNe \& Gascioigne 1960). According to EnEBo (1949) and F AHraeus (1949), certain cellulose-decomposing bacteria produce volatile acids, which retard and inhibit further decomposition of cellulose. If some other bacteria, not able to decompose cellulose, consume the acids, the fermentation time of cellulose is remarkably shortened. 
Several well-known cases are known among fungi of the mutual fulfillment of vitamin requirements (ORENSKI 1966), e.g. in $\mathrm{Ne}$ matospora gossypii and Polyporus sp. and in Mucor ramannianus and Rhodotorula rubra. If we consider the movements of carbohydrates in parasitic and mutualistic symbiosis (Smith, Muscaline \& Lewis 1969) secondary sugar fungi may represent one of the first stages in the development of dependence on other organisms in carbon nutrition. Similarly young seedlings of Dactylorchis are dependent on the cellulolytic ability of Rhizoctonia to release soluble carbohydrates from cellulose.

\section{Acknowledgements}

This investigation has been carried out at the Finnish Forest Research Institute under grants from U. S. Public Law 480, 83rd Congress.

\section{LITERATURE GITED}

Burges, A., 1939: Soil fungi and root infection. - Broteria 8, 64-81.

Cochrane, V. W., 1958: Physiology of fungi. New York. 524 pp.

Ciooney, D. G. \& R. Emerson, 1964: Thermophilic fungi. - San Francisco. $188 \mathrm{pp}$.

Deverall, B. J., 1968: Psychrophiles. - The Fungi, ed. by G. G. Ainsworth and A. S. Sussman, voll. III, 129-135.

EneBo, L., 1949: Symbiosis in thermophilic cellulose fermentation. - Nature 163, 805.

FAnraeus, G., 1949: Agrobacterium radiobacter Conn as a symbiont in cellulose decomposition. - Ann. Royal Agric. College of Sweden $16,159-166$.

Garrett, S. D., 1960: Biology of root-infecting fungi. - Cambridge. 293 pp.

- 1963: Soil fungi and soil fertility. - Oxford. $166 \mathrm{pp}$.

Gascoigne, J. A. \& M. M. Gascoigne, 1960: Biological degradation of cellulose. - London. 264 pp.

Grlman, J. C., 1957: A manual of soil fungi. Second edition. - Ames. Iowa, $450 \mathrm{pp}$.

Hawker, L.. 1947: Firther studies on growth and fruiting of Melanospora destruens Shear. in the presence of various carbohydrates with special reference to the effects of glucose and of sucrose. - Ann. of Bot. $11,245-260$.

HintıkкA, V., 1964: Psychrophilic basidiomycetes decomposing forest litter under winter conditions. - Comm. Inst. Forest. Fenn. 59: 2, $1-20$.

- 1970: Studies on white-rot humus formed by higher fungi in forest soils. - Ibid. 69: $2,1-68$.

Hudson, H. J., 1968: The ecology of fungi on plant remains above the soill. - New Phytologist 67, 837-874.

Ingold, C. T. \& M. H. ZoBeri, 1963: The axexual apparatus of Mucorales in relation to spore liberation. - Trans. Brit. Myc. Soc. 46, $115-134$

Mangenot, F., 195.2: Recherches méthodiques sur les champignons de certains bois en décomposition. - Rev. géner. de Bot. 59, $381-399,439-471,477-518,544-555$.
Naumov, N. A., 1954: Flora gribov Leningradskoi oblasti. - Moskva-Leningrad. 182 pp.

Nyкvist, N., 1963: Leaching and decomposition of water-soluble organic subsitances from different types of leaf and needle litter. - Studia Foresitalia Suecica 3, 1-31.

Orenski, S. W., 1966: Intermicrobial symbiosis. Symbiosis, ed. by S. M. Henry, vol. 1, 133. New York. 478 pp.

Penrson, S. O., 1948: Studies of the growth physiology of Phacidium infestans Karst. - Phys. Plant. 1, 38-56.

Puchko, A. 1966: Materials on the flora Mucoralles of the Latvian S.S.R. (In Russian). P. Stučka Latvian State university Scientific works, vol. 74, Botany, 2nd series, Riga, 101-109.

Schipper, M. A. A. and V. Hintikka, 1969: Zygorhynchus psychrophilus n. sp. - Antonie van Leeuwenhoek 35, 29-32.

Sru, R. G. H., 1951: Microbial decomposition of cellulose. - New York. 53,1 pp.

Smith, D., L. Muscaline \& D. Lewis, 1969: Carbohydrate movement from autotrophs to heterotrophs in parasitic and mutualistic symbiosis. - Biol. Rev. 44, 17-90.

Stevenson, I. L., 1964: Biochemistry of soil. Chemistry of the soil, ed. by F. E. Bear, 242-291.

Thом, C. \& M. B. Morrow, 1937: Fungus mycelia in soil. - J. Bact. 33, 77-78.

Togashi, K., 1949: Biological characters of plant pathogens. Temperature relations. - Tokyo. 479 pp.

VARtiovaARA, U., 1935: Maaperän sienten aineenvaihduntaa koskevia tutkimuksia. - Acta Agr. Fenn. 32, 1-112.

WaID, J. S., 1968: Physiological and biochemical adjustment of fungi to their environment. The Fungi, ed. by G. G. Ainsworth and A. S. Sussman, vol. III, 289-323. New York-London.

Williams, C. N., 1959: Spore size in relation to culture conditions. - Transactions of Brit. Mycol. Soc. 42, 213-222.

ZYCHA, H., 1963: Mucorineae. - Kryptogamenflora von Brandenburg, Band VIa: Pilze IT. 264 pp. Reprint, originally published in 1935. 